\title{
La idea kantiana de paz perpetua. Desde la distancia histórica de doscientos años *
}

\author{
JÜRGEN HABERMAS \\ Johann Wolfgang Goethe-Universität, Frankfurt
}

En el presente articulo se analiza la actualidad de la propuesta de construir un orden mundial pacifico perfilada por Kant en su opúsculo La paz perpetua, publicado en 1795. Aunque los fundamentos filosóficos que subyacen en este emblemático e influyente ensayo han sido problematizados y el marco histórico se ha transformado profudamente, obligando a una radical reformulación, siguen en gran medida vigentes los principales objetivos propuestos. A la luz de las ideas básicas del texto kantiano el autor examina algunas observaciones formuladas contra la política de derechos humanos, mostrándose especialmente crítico con las objeciones vertidas por Carl Schmitt contra el pacifismo jurídico.

La «paz perpetua» que el abate de Saint Pierre había postulado es para Kant un ideal que debe prestar atractivo y fuerza visible a la idea del orden cosmopolita. Con ello Kant introduce en la teoría del derecho una tercera dimensión, una innovación enriquecedora: junto al derecho estatal y al derecho internacional coloca el derecho cosmopolita. El orden republicano de un Estado constitucional basado en los derechos humanos exige no sólo una débil sujeción, propia del derecho internacional, de las relaciones internacionales, dominadas por las guerras. El orden jurídico en el interior de los Estados debe más bien culminar en un orden jurídico global que congregue a los pueblos y elimine las guerras: «La idea de una constitución en consonancia con los derechos naturales del hombre, a saber, que quienes obedecen la ley deben ser al mismo tiempo legisladores, está en la base de todas las formas políticas, y la comunidad conforme a ella ... se denomina ideal platónico, no es una vana quimera, sino la norma eterna para cualquier constitución civil en general, y aleja toda guerra» (Streit der Fakultäten, Werke VI, 364; IHU, 95) ${ }^{\text {. }}$. La consecuencia es sorprendente: “... y aleja toda guerra». Indica que las normas del derecho internacional, que regulan la paz y la guerra, sólo deben valer tran-

* Este artículo apareció originalmente, con el título kKants Idee des Ewigen Friedens-aus dem historischen Abstand won 200 Jahren", en la revista Krísche Justiz, núm. 3 (1995), Frankfurt A. M., pp. 293-319. Traducción y notas de Juan Carlos Velasco Arroyo.

'A continuación cito por la edición a cargo de W. Weischedel de la Wissenschaftlichen Buchgesellschaft Darmstadt, Insel-Verlag, Francfort, 1964. Las menctones sin título se refieren al ensayo "Zum ewigen Friedens, Werke VI, pp. 195-251. [Las referencias de los textos kantianos en castellano se indicarán con las siguientes abreviaturas: IHU = Ideas para una historia universal en clave cosmopolita y otros excritos sobre Filosofia de la Historia, Tecnos, Madrid, 1987; MC = La metafisica de las costambres, Tecnos, Madrid, 1989; PP = Sabre la paz perpetua, Tecnos, Madrid, 1985; TP = Teoria y práctica, Tecnos, Madrid, 1986 (N. del T.)l. 
sitoriamente, es decir, hasta que el pacifismo jurídico, por el que Kant transita con su escrito La paz perpetua, haya creado un orden cosmopolita y con ello la abolición de la guerra.

Kant desarrolla esta idea, por supuesto, con la terminología propia del derecho racional y en el horizonte de experiencias de su tiempo. Ambas cosas nos separan de Kant. Con la arrogancia gratuita de los nacidos después sabemos hoy que la construcción propuesta adolece de dificultades conceptuales y ya no resulta apropiada para nuestras experiencias históricas. Por eso recordaré en primer lugar las premisas de las que parte Kant. Afectan a los tres pasos de su argumentación: tanto a la definición del objetivo inmediato, la paz perpetua; a la descripción del propio proyecto, la forma jurídica de la federación de pueblos; así como a la solución de filosofía de la historia, y con ello al problema planteado, la realización de la idea de un orden cosmopolita (I). A eso se añade la cuestión de cómo se presenta la idea kantiana a la luz de la historia de los últimos doscientos años (II) y cómo esta idea debe ser reformulada en relación a la actual situación mundial (III). La alternativa propuesta por juristas, politólogos y filósofos para evitar volver al estado de naturaleza ha levantado objeciones contra el universalismo del derecho cosmopolita y de la política de los derechos humanos, objeciones que pueden ser debilitadas mediante la adecuada distinción entre derecho y moral en el concepto de derechos humanos (IV). Esta distinción ofrece también la clave para una metacrítica de los exitosos argumentos, tan eficaces histöricamente, de Carl Schmitt contra los fundamentos humanísticos del pacifismo jurídico (V).

Kant determina negativamente el objetivo del pretendido aorden legals entre los pueblos como eliminación de la guerra: «No debe haber guerra», debe concluir el «infernal y desesperado hacer la guerra» ( «Beschluß» der Rechtslehre, Werke IV, 478; «Conclusión» de la Doctrina del Derecho, MC, 195). Kant basa la deseabilidad de esa paz en los males producidos por aquella clase de guerra emprendida por los soberanos europeos de entonces con la ayuda de sus mercenarios. Entre esos males no nombra en primer lugar a las víctimas mortales, sino el «horror de la actividad violenta», las «devastaciones», sobre todo los expolios y el empobrecimiento del país debido a las cuantiosas contribuciones de la guerra y, como posibles consecuencias de la guerra, el sometimiento, la pérdida de la libertad, el dominio extranjero. A eso se añade el embrutecimiento de las costumbres cuando los súbditos son instigados por el Gobierno a acciones ilegales (por ejemplo, a convertirse en francotiradores o en asesinos), al espionaje o a la propagación de falsas noticias o al disimulo. Aquí se muestra el panorama de la guerra limitada, que desde la Paz de Westfalia de 1648 se había institucionalizado mediante cl derecho internacional en un sistema de potencias como un medio legítimo de solución de conflictos. La terminación de una guerra como tal define el estado de paz. Del mismo modo que un determinado tratado de paz termina con el mal de una única guerra, así ahora una asociación de paz debe eliminar «toda guerra 
para siempre» y el mal de la guerra como tal. Este es el significado de la xpaz perpetua». La paz está tan limitada como la guerra misma.

Kant pensaba en conflictos limitados espacialmente entre Estados individuales y alianzas, no todavía en guerras mundiales. Pensaba en conflictos entre gabinetes y Estados, no todavía en guerras civiles. Pensaba en guerras limitadas técnicamente, que permitian la diferencia entre tropas combatientes y población civil, todavía no en luchas de partisanos y en el terror de las bombas. Pensaba en guerras con objetivos limitados políticamente, no todavía en guerras de aniquilación y expulsión motivadas ideológicamente ${ }^{2}$. Bajo las premisas de la guerra limitada, las normas del derecho internacional se refieren a la dirección de la guerra y a la regulación de la paz. El derecho «a la guerra» propuesto delante del derecho «en la guerra» y «después de la guerra», el así denominado ius ad bellum, no es estrictamente un derecho, porque sólo es expresión del libre arbitrio, que corresponde a los sujetos del derecho internacional en el estado de naturaleza, esto es, en el estado alegal de las relaciones entre ellos (Werke VI, 212). Las únicas leyes penales -incluso aunque sólo sean ejecutadas por los tribunales de los Estados en conflictoque intervienen en ese estado alegal se refieren a la conducta en la guerra. Los crímenes de guerra son crimenes perpetrados en la guerra. Sólo la limitación de la guerra, producida entretanto, y la correspondiente ampliación del concepto de paz suscitan la idea de que la guerra misma -en la forma de guerra de agresiónes un crimen que ha de ser proscrito y castigado. Para Kant no había aún crimen de guerra.

La paz perpetua es una característica importante del orden cosmopolita, pero es tan sólo un síntoma del mismo. El problema conceptual que Kant debe solucionar es la conceptualización jurídica de ese orden. Debe señalar la diferencia entre el derecho cosmopolita y el clásico derecho internacional, esto es, debe señalar lo específico de ese ius cosmopoliticum.

Mientras que el derecho internacional, como todo derecho en el estado de naturaleza, vale tan sólo transitoriamente, el derecho cosmopolita, como el derecho sancionado estatalmente, acabaría definitivamente con el estado de naturaleza. Por eso para llegar hasta el orden cosmopolita Kant se sirve continuamente de la analogia con aquella primera salida del estado de naturaleza, que mediante la constitución contractualista de un determinado Estado posibilita a los ciudadanos del país una vida en libertad asegurada por medios legales. Como en aquel caso se había acabado con el estado de naturaleza entre los individuos enfrentados entre sí, así debe también terminar el estado de naturaleza entre los Estados belicistas. En un tratado publicado dos años antes de La paz perpetua señala entre

\footnotetext{
${ }^{2}$ Aunque menciona en la Doctrina del Derecho al kenemigo injusto*, cuya evoluntad públicamente expresada denota una máxima según la cual si se convirtiera en regla universal sería imposible un estado de paz entre los pueblos» ( $\$ 60$ Werke IV, $473 ; \mathrm{MC}, 189$ ), los ejemplos que aduce, tales como la ruptura de los tratados de derecho internacional o la división de un país ocupado (como en su tiempo Polonia), iluminan la relevancia accidental de ese concepto. Una «guerra punitiva contra enemigos injustos sigue siendo un pensamiento inconsecuente mientras contemos con Estados soberanos absolutos, pues éstos no pueden reconocer una instancia judicial que juzgue imparcialmente sobre violaciones de reglas en las relaciones interestatales sin menoscabar su sobcranía. Unicamente victoria y derrota deciden «de qué lado está el derecho* (Werke VI, 200; PP, 10).
} 
ambos procesos un estrecho paralclismo. También aquí alude a la destrucción de la prosperidad y a la pérdida de la libertad como el gran mal, para proseguir luego: «Ahora bien: contra esto ningún otro remedio es posible (por analogía con el derecho civil o con el político de los hombres tomados individualmente) salvo el de un derecho internacional fundado en leyes públicas con respaldo de un poder, leyes a las cuales todo Estado debería someterse, pues una paz universal duradera conseguida mediante el así llamado equilibrio de las potencias en Europa es...una mera quimera" (Werke VI, 172; TP, 59). El discurso no es todavía aquí sobre un «Estado universal de los pueblos bajo cuyo poder todos los Estados deben consentir voluntariamente». Pero apenas dos años despućs Kant diferencia cuidadosamente entre «asociación de naciones» (Völkerbund) y aEstado de naciones» (Völkerstaat).

El orden designado en lo sucesivo como «cosmopolita» debe diferenciarse del estado jurídico intraestatal, a saber, que los Estados no deben someterse como ciudadanos individuales a leyes públicas de un poder superior, sino que mantienen su independencia. La federación prevista de Estados libres, que eliminan el mecanismo de la guerra de una vez por todas mediante las relaciones entre ellos, debe dejar intacta la soberanía de sus miembros. Los Estados asociados mantienen a la larga su competencia de atribuir competencias (Kompetenz-Kompetenz) y no quedan absorbidos por una república mundial configurada mediante cualidades estatales. En vez de la «idea positiva de una república mundial» se trata del «sucedáneo negativo de una federación protectora de la guerras (Werke VI, 213; PP, 26). Esta federación debe proceder de los actos de voluntad libre de los tratados internacionales, que ahora ya no tienen que ser pensados según el modelo del contrato social. Pues los tratados no fundamentan ninguna pretensión jurídica reclamable de los miembros, sino que vinculan a éstos sólo por medio de una alianza existente a la larga, por medio de una «asociación continuamente libre». Así este acto de asociación a una federación de Estados excede a la débil fuerza vinculante del derecho internacional, es sólo la señal de «permanencia». Kant compara luego también la asociación de naciones con un «congreso permanente de Estados» (Rechtslehre, \$ 61; MS, 350; MC, 191).

Resulta evidente la contradicción de esta construcción, pues en otro lugar Kant entiende por congreso «sólo una confederación arbitraria de diversos Estados, disoIuble en cualquier momento, no una unión que (como la de los Estados norteamericanos) esté fundada...en una constitución estatals (Rechtslchre, Werke IV, 475; MC, 191). Kant no explica, empero, cómo puede ser garantizada la permanencia de la asociación, de la que depende el arreglo «de manera civil» de los conflictos internacionales, sin el carácter obligatorio propio de una institución análoga a una constitución. Quiere, por un lado, proteger la soberanía de los miembros mediante la reserva de disolubilidad del contrato. Esto es lo que sugiere la comparación entre congresos y asociaciones voluntarias. Por otro lado, la federación, que establece la paz de manera duradera, debe diferenciarse de las alianzas pasajeras en que los miembros se sienten obligados, en el caso de que hubiera que someter la propia razón de Estado al objetivo declarado en común, «a resolver sus disputas mediante un procedimiento, no mediante guerra», Sin este momento de obligación 
el congreso pacífico de las naciones no puede proseguir de modo permanente, ni la asociación voluntaria de modo continuo, sino que permanece secuestrado por la inestable constelación de intereses y decaerá - como más tarde la Sociedad de Naciones de Ginebra- Kant no puede concebir una obligación jurídica, porque su asociación de naciones (Völkerbund) no está pensada como una organización que con órganos comunes adquiere cualidad estatal, y en cuanto tal una autoridad coercitiva. Debe confiar por eso tan sólo en una autovinculación moral de los Gobiernos. Esto apenas se puede conciliar con las descripciones kantianas crudamente realistas de la política contemporánea.

El propio Kant comprende ciertamente el problema, pero simultáneamente lo encubre con una mera apelación a la razón: «Si (un) Estado dice: "no debe haber ninguna guerra entre otros Estados y yo, aunque no reconozco ningún poder legislativo supremo que asegure mi derecho y al que yo asegure su derecho", no puede, entonces, entenderse en absoluto dónde quiero basar la confianza en mi derecho si no existe el sustituto de la federación de las sociedades civiles, es decir, el federalismo libre, al que la razón debe vincular necesariamente con el concepto del derecho de gentes» (Werke VI, 212; PP, 25). Esta seguridad puede abrir, no obstante, una cuestión decisiva: cómo, pues, puede ser asegurada la permanencia de la autovinculación de los Estados, que como soberanos siguen existiendo. Esto no se refiere todavía a la pregunta empírica de la aproximación a esta idea, sino a la misma forma conceptual de esta idea. Si la asociación de naciones no debe ser una organización moral, sino jurídica, entonces no le deben faltar aquellas cualidades de una «buena constitución estatal», que Kant explica pocas páginas después: cualidades de una constitución que no tiene que confiarse a «la buena formación moral» de sus miembros, sino que ésta, por su parte, puede ser fomentada, en el mejor de los casos, por una buena constitución.

Considerada históricamente, la cautela de Kant frente al proyecto de una comunidad constituida de pueblos era ciertamente realista. El Estado democrático de derecho era entonces una excepción, no una regla. El sistema de potencias funcionaba bajo el presupuesto de que sólo los Estados soberanos podían ser sujetos del derecho internacional. Soberanía externa significa la capacidad de un Estado de afirmar en la arena internacional su independencia, esto es, la integridad de las fronteras en caso de necesidad con la fuerza militar. Soberanía interna significa la capacidad apoyada en el monopolio de la violencia de mantener la paz y el orden en el propio país con medios del poder administrativo y del derecho positivo. La razón de Estado se determina según los principios de una política de expansión (Machtpolitik) que incluye guerras limitadas y prudentes, en donde la política interior está bajo el primado de la política exterior. La clara distinción entre política exterior e interior se basa en un concepto estrecho y políticamente selectivo del poder que se ajusta en último lugar a la disposición del poseedor del poder a través del poder acuartelado del ejército y la policía.

En tanto que este mundo clásico-moderno de los Estados determine el horizonte infranqueable debe aparecer como no realista aquella perspectiva de una constitución cosmopolita que no respeta la soberanía de los Estados. Eso explica también por qué la posibilidad de una unión de pueblos bajo la hegemonía de un Estado 
poderoso, que Kant jlustra mediante la imagen de una «monarquía universal» (Werke VI, 247), no representa una alternativa: bajo las mencionadas premisas una potencia directora tal debería acarrear el «más horrible despotismo» (Werke, VI, 169). Porque Kant no sobrepasa ese horizonte contemporáneo de experiencias es ciertamente difícil creer en una motivación moral para la creación y mantenimiento de una federación de Estados libres comprometidos en una política de expansión. Para la solución de este problema propone Kant una filosofía de la historia en clave cosmopolita que debe hacer plausible a primera vista la aconciliación de la política con la moral» a partir de un escondido «designio de la naturaleza».

\section{II}

Kant nombra tres tendencias que deben aclarar por qué una asociación de naciones podría ser de interés propio para los Estados: 1) la naturaleza pacífica de las repúblicas; 2) la fuerza asociativa del comercio mundial, y 3) la función de la esfera pública política. Una mirada histórica a estos argumentos resulta instructiva en un doble sentido: por un lado, el contenido de su significado manifiesto ha sido falseado a lo largo de los siglos xix y xx; por otro lado, llaman la atención sobre las evoluciones históricas que relatan una dialéctica singular. A saber: estas evoluciones muestran, por una parte, que las premisas en las que Kant basó su teoría bajo las condiciones percibidas en los años finales del xvir ya no se corresponden con la realidad; pero, por otra parte, hablan también a favor de que una concepción reformulada y adaptada a nuestro tiempo del derecho internacional - según como interpretemos las condiciones cambiantes de los años finales del siglo $\mathrm{xx}$ - podría valer para una constelación favorable de fuerzas.

1) El primer argumento afirma que en la medida en que las relaciones internacionales pierden su carácter belicista la forma de gobierno republicana se extiende por los Estados, pues las poblaciones de los Estados constitucionales democráticos estimulan, por interés propio, a sus Gobiernos a proseguir una política pacifista: «Si es preciso el consentimiento de los ciudadanos [...] para decidir si debe haber guerra o no, nada es más natural que se piense mucho el comenzar un juego tan maligno, puesto que ellos tendrían que decidir para sí mismos todas las calamidades de la guerra» (PP, 17). Esta optimista concepción ha sido desmentida por la fuerza movilizadora de una idea que Kant en 1795 no podía todavía conocer en su ambivalencia. El nacionalismo era ciertamente un vehículo para la deseada transformación de los súbditos en ciudadanos activos, que se identifican con su Estado. Pero esto no ha hecho al Estado democrático nacional más pacífico que su predecesor, el Estado autoritario dinástico ${ }^{3}$. Desde el punto de vista de los movimientos nacionales, la clásica autoafirmación del Estado soberano adquiere la connotación de libertad e independencia nacional. Por eso la conciencia republicana del ciudadano debía probarse en la disposición a luchar y morir por el

\footnotetext{
${ }^{3}$ H. Schulze, Staat und Nation in der Europäischen Geschichte, Munich, 1994.
} 
pueblo y la patria. Kant veía en los mercenarios de su tiempo, no sin motivo, instrumentos «al uso de los hombres como meras máquinas ... en manos de otros» y exigió el empleo de milicias; no pudo prever que la movilización masiva de soldados conscriptos inflamados de sentimiento nacionalista podría conducir a una época de guerras de liberación desvastadoras e ideológicamente ilimitadas.

Por otro lado, tampoco es totalmente falso el pensamiento de que una situación democrática en el interior sugiere una conducta pacifista del Estado hacia fuera. Investigaciones histórico-estadísticas muestran que aunque los Estados constituidos democráticamente no tienen menos guerras que los regímenes autoritarios (de una u otra clase), se comportan empero en las relaciones entre sí de modo menos belicista. Ese resultado admite una interesante interpretación ${ }^{4}$. En la medida en que las orientaciones valorativas de carácter universalista de una población acostumbrada a instituciones libres impregnan también la política externa, una comunidad republicana no se comporta de una manera más pacífica en su conjunto, pero las guerras que lleva a cabo cambian su carácter. Con las motivaciones de los ciudadanos cambia también la política exterior del Estado. La utilización de la fuerza militar ya no está determinada en exclusiva por una razón de Estado esencialmente particularista, sino también por el deseo de fomentar la expansión de formas no autoritarias de Estado y de gobierno. Si, en cambio, se amplían las preferencias valorativas, más allá de la percepción de los intereses nacionales, en favor de la puesta en marcha de la democracia y de los derechos humanos, cambian las condiciones bajo las cuales funciona el sistema de potencias.

2) De un modo dialéctico semejante se ha comportado la historia, que consideramos entretanto, con el segundo argumento. Kant se equivocó directamente, pero de manera indirecta también tuvo razón. Así, en la creciente interdependencia de las sociedades reforzada por el tráfico de informaciones, personas y mercancías y especialmente en la expansión del comercio, Kant percibió una tendencia en favor de la asociación pacífica de los pueblos. Las relaciones comerciales que se ampliaron en la temprana Edad Moderna tomaron cuerpo en un mercado mundial que, según su concepción, debería fundamentar «mediante el mutuo provecho propio» un interés en asegurar las relaciones pacíficas: «Se trata del espíritu comercial que no puede coexistir con la guerra y que, antes o después, se apodera de todos los pueblos. Como el poder del dinero es en realidad el más fiel de todos los poderes subordinados al poder del Estado, los Estados se ven obligados a fomentar la paz» (Werke VI, 226; PP, 41). Kant todavía no había aprendido, obviamente - como pronto lo haría Hegel de su lectura de los economistas ingleses- ${ }^{5}$ que el desarrollo capitalista podría conducir a la oposición de clases sociales, que amenaza a la paz y a la presunta disposición pacífica de las sociedades políticamente liberales de un modo doble. Kant no previó que las tensiones sociales que se fortalecerían a lo largo de una acelerada industrialización capitalista podrían cargar a la política interior con las luchas de clase y orientar a la política exterior por las vías de un imperialismo belicista. A lo largo del siglo xix y primera mitad

${ }^{4}$ D. Archibugi, D. Held (eds.), Cosmopolitan Democracy, Cambridge, 1995, «Introduction», pp. 10 yss.

s Georg Iukacs, Der junge Hegel, Zürich, 1948. 
del xx los Gobiernos europeos se han servido del impulso del nacionalismo para desviar los conflictos sociales hacia fuera y neutralizarlos mediante éxitos en la política exterior. Sólo después de las catástrofes de la Segunda Guerra Mundial, cuando se agotaron las fuentes energéticas del nacionalismo integral, una pacificación exitosa de los antagonismos de clase llevada a cabo por el Estado social ha cambiado de tal modo la situación interna de las sociedades desarrolladas que -al menos en el ámbito de la OCDE - la interdependencia económica entre las economias nacionales podía conducir a aquel modo de «economización de la política internacionals ${ }^{6}$ a la que Kant había asignado correctamente una eficacia pacificadora. Hoy los medios de comunicación, redes y sistemas a escala mundial fuerzan el adensamiento de las relaciones simbólicas y sociales, ocasionando así el influjo recípocro entre sucesos locales y otros bien distantes ${ }^{7}$. Estos procesos de globalización hacen cada vez más vulnerables a las sociedades complejas con su delicada infraestructura técnica. Mientras que los conflictos militares entre las grandes potencias nucleares se hacen cada vez más improbables debido a los costosos riesgos, abundan empero los conflictos locales con víctimas comparativamente copiosas y atroces. De otro lado, la globalización pone en cuestión los presupuestos esenciales del derecho internacional clásico: la soberanía de los Estados y las nítidas distinciones entre política interior y exterior.

Actores no estatales, tales como las empresas transnacionales y los bancos privados, influyentes internacionalmente, socavan la soberanía formal de los Estados nacionales. Hoy, cada una de las treinta mayores empresas que operan en el mundo tiene un movimiento anual superior al Producto Nacional Bruto de noventa países representados en la ONU. Pero incluso los Gobiernos de los países más poderosos económicamente perciben el abismo que se abre entre el espacio económico limitado nacionalmente y los imperativos, no del comercio mundial, sino de las relaciones de producción entramadas globalmente. Los Estados soberanos sólo pucden aprovecharse de sus economias mientras sean «economias nacionales» sobre las que pueden influir con medios políticos. Con la desnacionalización de la economía, especialmente con los mercados de finanzas que expanden sus redes por todo el mundo y con la misma producción industrial, pierde la política nacional dominio sobre las condiciones generales de producción ${ }^{8}$ (y con ello el timón para el mantenimiento del nivel social alcanzado).

Simultáneamente se diluyen para los Estados soberanos los límites constitutivos entre política interior y exterior. La imagen de la política de expansión clásica no ha cambiado tan sólo a través del punto de vista normativo complementario de la política de democratización y de derechos humanos, sino a través de la propia difusión del poder. Bajo la creciente presión a la cooperación gana en importancia la toma de influencia más o menos indirecta sobre la estructuración de las situaciones más perceptibles, la producción de contactos o la interrupción

- Dieter Senghaas, «Internationales Politik im Lichte ihrer strukturellen Dilemmata*, en idem, Wohm driftet die Well?, Francfort, 1994, pp. 121 y ss., 132.

${ }^{7}$ Así define A. Giddens aglobalización en The Consequences of Modernity, Cambridge, 1990, 64 [hay trad castellana: Consecuencias de la modernidad, Madrid, Alianza, 1993, pp. 67 y 68 (N. del T.)].

* R. Knieper, Nationale Souveränität, Francfort, 1991. 
de corrientes de comunicación, así como sobre la definición de la agenda y los problemas. A menudo es más importante la toma de influencia sobre las condiciones marco, en las que otros actores toman sus decisiones, que la realización directa de los propios fines, el ejercicio de poder administrativo o la amenaza de violencia?. El soft power reprime al hard power y priva de la base de su independencia a aquellos sujetos sobre los que estaba perfilada la asociación kantiana de Estados libres.

3) De un modo parecido se comporta con el tercer argumento que Kant pone en juego para debilitar la sospecha de que la proyectada federación de pueblos es meramente una «idea quimérica». En una comunidad republicana los principios constitucionales forman criterios por medio de los cuales se puede enjuiciar públicamente la política. Esos Gobiernos no se pueden prestar «a basar abiertamente la política en los asideros de la prudencia» (Werke VI, 238; PP, 54), incluso si sólo fuera necesario decirlo de boquilla. La esfera pública burguesa posee entretanto una función controladora: puede impedir por medio de la crítica pública la perpetración de las intenciones más temibles que no sean conciliables con máximas defendibles públicamente. Según la concepción de Kant, la esfera pública debe adquitir incluso una función programática en tanto que los filósofos en calidad de «enseñantes públicos del derecho» o de intelectuales pueden hablar «libre y públicamente sobre máximas de la guerra y del establecimiento de la paz» y convencer al público ciudadano de sus principios generales. Kant tenía ante los ojos el ejemplo de Federico II y Voltaire cuando escribió la tranquilizadora frase: «No hay que esperar que los reyes filosofen ni que los filósofos sean reyes, como tampoco hay que desearlo, porque la posesión del poder daña inevitablemente el libre juicio de la razón. Pero es imprescindible - y nada sospechoso- para ambos que los reyes, o los pueblos soberanos, que se gobiernan a sí mismos por leyes de igualdad, no dejen desaparecer o acallar a la clase de los filósofos, sino que los dejen hablar públicamente para aclaración de sus asuntos» (Wcrke VI, 228; PP, 43-44).

Como la polémica del ateísmo de Fichte mostró poco después, Kant tenía buenas razones para temer la censura. También debemos disculparle la confianza puesta en la fuerza de convicción de la filosofía y en la probidad de los filosofos; el escepticismo histórico frente a la razón pertenece sólo al siglo xIX, y sólo en nuestro siglo los intelectuales cometieron la gran traición. Lo que resulta más importante: Kant contaba todavía con la transparencia de una esfera pública abarcable, conformada literariamente, accesible a los argumentos, compuesta por un público de una capa comparativamente pequeña de ciudadanos cultos. No podía prever el cambio estructural de esta esfera pública burguesa a una esfera pública dominada por los medios de masas electrónicos, degenerada semánticamente, ocupada de imágenes y realidades virtuales. No podía ni sospechar que este milieu de una ilustración «habladora» pudiera cambiar de función tanto por una indoctrinación sin palabras como por un engaño con palabras.

Probablemente este velo de ignorancia explica la audacia de la anticipación adelantada y, como hoy sabemos, clarividente de una esfera pública mundial. Pues ésta se perfila tan sólo ahora como consecuencia de la comunicación global: «Como

\footnotetext{
*. S. Nye, «Soft Power», cn Foreign Policy, 80, 1990, pp. 153-171.
} 
se ha avanzado tanto en el establecimiento de una comunidad ... entre los pueblos de la tierra (!) que la violación del derecho en un punto de la tierra repercute en todos los demás, la idea de un derecho cosmopolita no resulta una representación fantástica ni extravagante, sino un necesario complemento... del derecho político y del derecho de gentes mediante unos públicos derechos humanos en general y asimismo un complemento de la paz perpetua, a la que sólo bajo esta condición (a saber: una esfera pública mundial en funcionamiento, J. H.) puede aproximarse de un modo continuo" (Werke VI, 216; PP, 30).

Los primeros acontecimientos que de hecho atrajeron la atención de una esfera pública global y polarizaron las opiniones a escala mundial fueron, presuntamente, la guerra del Vietnam y la guerra del Golfo. Sólo recientemente la ONU ha organizado una conferencia detrás de otra sobre cuestiones de alcance planetario: la ecología (en Río de Janeiro), los problemas del crecimiento demográfico (en El Cairo), la pobreza (en Copenhague) y el clima (en Berlín). Podemos entender estas «cumbres mundiales» como intentos de ejercer al menos una cierta presión política sobre los Gobiernos a través de la tematización de Ios más importantes problemas para la supervivencia en una esfera pública mundial, esto es, a través de un llamamiento a la opinión mundial. No sc pucde desconocer, empero, que esa atención provocada temporalmente sobre temas específicos ha de ser canalizada por medio de las esferas públicas nacionales que funcionen. La comunicación continuada entre participantes alejados en el espacio que intercambian simultáneamente temas iguales de igual relevancia precisa estructuras que funcionen. En este sentido no existe todavía una esfera pública global, ni siquiera la urgente y necesaria esfera pública a nivel europeo. Pero el papel central que las organizaciones de nuevo tipo, a saber, las organizaciones no gubernamentales como Greenpeace o Amnesty International, juegan no sólo en esas conferencias, sino en general en la producción y movilización de opiniones públicas supranacionales, es al menos un síntoma de una creciente influencia publicista de actores que se enfrentan a los Estados como si ya constituyeran una sociedad civil entramada internacionalmente ${ }^{10}$.

El papel de la publicidad y de la esfera pública, realzado correctamente por Kant, orienta la mirada sobre la conexión de la constitución jurídica con la cultura política de una comunidad ${ }^{11}$. Una cultura política liberal forma el suelo en donde echan raíces las instituciones de libertad y es, al mismo tiempo, el medio en donde se efectúan los progresos en la civilización política de una población ${ }^{12}$. Ciertamente Kant habla del «incremento de cultura», que conduce a «un más amplio acuerdo sobre los principios» (Werke VI, 226; PP, 40-41); esperaba también que el uso público de las libertades comunicativas se convirtieran en un proceso de ilustración que fijase sobre la socialización política las convicciones y formas de pensar de una población. En este contexto habló de «la parte de corazón que el hombre

\footnotetext{
"Sobre el «adiós al mundo de los Estados», cfr. E. O. Czempiel, Welpolitik im Umbruch, Munich, 1993 , pp. 105 y ss.

$"$ "Cfr. los articulos de Abrecht Wellmer y Axel Honneth en M. Brumlik y H. Brunkhorst (cds.), Gemeinschaft und Gerechtigkeit, Francfort, 1993, pp. 173-196 y 260-270.

${ }^{12}$ Cfr, el artículo que da titulo al libro, J. Habermas, Die Nomaliät einer Berliner Repubik, Francfort, 1995, pp. 167-188.
} 
ilustrado no puede sustraerse a poner en el bien al comprenderlo perfectamente» (Werke VI, 46; IHU, 19). Pero esta observación no tiene ningún significado sistemático, porque la formación dicotómica de los conceptos propia de la filosofía trascendental separa lo interior de lo exterior, la moralidad de la legalidad. Kant desconoce la conexión que provoca una cultura política liberal entre percepción intcligente de intereses, visiones morales y costumbres, entre tradición de un lado y crítica de otro. Las prácticas de una cultura tal vinculan a la moral, al derecho y a la política y forman simultáneamente un contexto apropiado para una csfera pública que impulsa un proceso político de aprendizaje ${ }^{\text {is }}$. Por eso Kant no podría remitirse a una intención metafísica de la naturaleza para explicar cómo «un acuerdo social urgido patológicamente se puede transformar en un todo moral» (Werke VI, 46; IHU, 9).

Estas reflexiones críticas muestran que la idea kantiana de un orden cosmopolita deben ser reformuladas si no quieren perder el contacto con una situación mundial modificada sustancialmente. La necesaria revisión del marco conceptual básico se ve facilitada porque la idea misma no ha permanecido, por así decir, quieta. Desde la iniciativa del presidente Wilson y la fundación de la Sociedad de Naciones esa idea se ha incorporado a la política y se ha puesto en práctica. Después de la Segunda Guerra Mundial la idea de la paz perpetua ha encontrado forma concreta en las instituciones, declaraciones y politicas de las Naciones Unidas. La fuerza desafiante de las incomparables catástrofes del siglo $\mathrm{xx}$ ha dado un impulso a la idea. Ante este sombrío panorama, el espíritu del mundo, como se hubiera expresado Hegel, se habría estremecido.

La Primera Gucrra Mundial confrontó a las sociedades europeas con los horrores y espantos de una guerra geográfica y tecnológicamente ilimitada, y la Segunda Guerra Mundial con los crímenes masivos propios de una guerra ideológicamente ilimitada. Tras el velo de la guerra total maquinada por Hitler se completó una ruptura de la civilización, que ha provocado un cstremecimiento mundial y ha exigido el tránsito desde el derecho internacional al derecho cosmopolita. Por un lado, los tribunales militares de Nuremberg y Tokio convirtieron la proscripción de la guerra proclamada por el pacto de Kellogg ${ }^{14}$ en un delito penal. No se limitaron a los crímenes en la guerra, sino que incriminaron a la guerra misma como delito. Desde entonces puede ser perseguido el «crimen de guerra». Por otro lado, las leyes penales han sido ampliadas a los «crímenes contra la humanidad», a los crímenes que son ordenados legalmente por órganos del Estado y son ejecutados bajo la ayuda de incontables miembros de organizaciones, funcionarios,

${ }^{13}$ Sobre el «pueblo como soberano que aprende», cfr. H. Brunkhorst, Demokratie und Difforenz, Francfort, 1994, pp. 199 y ss.

14 El 27 de agosto de 1928 quince Estados firmaron cl Pacto de París, conocido popularmente como Pacto Kellogg-Briand. Además de condenar el recurso a la guerra para la resolución de los conflictos internacionales los firmantes renunciaban a la guerra «como instrumento de política nacional\%. Pronto fue ratificado prácticamente por todos los miembros de la Socicdad de Naciones, incluso Alemania, Japón e Italia (N. del $Y$.). 
hombres de negocios y personas privadas. Con estas dos novedades los sujetos estatales del derecho internacional han perdido por primera vez la presunción de inocencia de un supuesto estado de naturaleza.

La revisión de los conceptos fundamentales afecta a la soberanía exterior de los Estados y al carácter cambiante de las relaciones interestatales, 1); a la soberanía interna de los Estados y a las limitaciones normativas de la clásica política de expansión, 2); así como a la estratificación de la sociedad mundial y a una globalización de las amenazas que hacen necesaria una reconceptualización de aquello que entendemos como «paz», 3).

1) El concepto kantiano de una asociación de naciones respetuosa a la larga con la soberania de los Estados no es consistente. El derecho cosmopolita debe estar tan institucionalizado que vincule a los diferentes Gobiernos. La comunidad internacional debe poder obligar a sus miembros, bajo amenaza de sanciones, al menos a un comportamiento acorde con el derecho. Sólo con esto el inestable sistema basado en la amenaza recíproca de Estados soberanos que se autoafirman puede transformarse en una federación con instituciones comunes que asuma las funciones estatales, esto es, que regule jurídicamente el intercambio de sus miembros entre sí y controle el cumplimiento de estas reglas. La relación cxtcrna de los intercambios internacionales regulados contractualmente entre Estados que forman el entorno para los otros se transforma, pues, en una relación interna basada en un estatuto o constitución. Este sentido tiene la Carta de las Naciones Unidas que prohíbe las guerras ofensivas (con la prohibición de la violencia en el art. 2.4) y autoriza al Consejo de Seguridad a tomar medidas apropiadas y, en caso de necesidad, acciones militares si kexiste una amenaza de la paz, un quebrantamiento de la paz o un acto de agresión» (capítulo VII). De otro lado, a las Naciones Unidas les está expresamente prohibido intervenir en los asuntos internos de los Estados (art. 2.7). En diciembre de 1991 la Asamblea General confirmó este principio (en su resolución 46/182): «La soberanía, la integridad territorial y la unidad nacional de un Estado deben ser respetadas plenamente en concordancia con la Carta de las Naciones Unidas» ${ }^{15}$.

Mediante estas regulaciones ambiguas que simultáneamente limitan y garantizan la soberanía de cada Estado, la Carta toma en consideración una situación tran-

15. Isensee defiende una prohibición de intervención cualificada ucontra la creciente tendencia hacia el enternecimiento» con la sorprendente construcción de los «derechos fundamentales del Estados, en «Weltpolizei für Menschenrechte», Juristiche Zeizung, 1995, 9, pp. 421-430. «Lo que vale para los derechos fundamentales de los individuos vale, mutatis mutandis, también para los "derechos fundamentales" de los Estados, especialmente para su igualdad soberana, su autodeterminación qua soberano sobre personas y territoriom (424; con igual sentido, 429). La analogía entre la soberania de los Estados reconocidos por el derecho internacional y la libertad de las personas físicas desconoce no sólo el valor fundamental de los derechos subjetivos individuales y el patrón individualista de los modernos ordenamientos jurídicos, sino también el sentido específicamente jurídico de los derechos humanos como derechos subjetivos de los ciudadanos de un orden cosmopolita. 
sitoria. Las Naciones Unidas no disponen aún de fuerzas armadas propias, ni de otras que pudieran usar bajo su mando, ni finalmente del monopolio de la violencia. Para la puesta en práctica de sus acuerdos depende de la cooperación voluntaria de sus miembros capaces de actuar. La falta de una base de poder debía ser compensada mediante la configuración de un Consejo de Seguridad que acoge como miembros permanentes en la organización mundial a las grandes potencias provistas del derecho de veto. Es bien conocido que esto ha conducido a que durante décadas las superpotencias se hayan bloqueado recíprocamente. Cuando el Consejo de Seguridad adopta iniciativas hace un uso altamente selectivo de su espacio de juego discrecional bajo el desprecio del principio de igual tratamiento ${ }^{16}$. Este problema adquirió actualidad por la guerra del Golfo ${ }^{17}$. También el Tribunal Internacional de Justicia, con sede en La Haya, posee sólo una importancia simbólica, cuando no totalmente banal, pues sólo actúa a instancia de parte y los Gobiernos no están vinculados por sus sentencias (como se ha mostrado de nuevo en el caso de Nicaragua vs. Estados Unidos).

La seguridad internacional se garantiza hoy, al menos en las relaciones entre las potencias, con armas nucleares; no a través del marco normativo de la ONU, sino mediante acuerdos de control de armamentos, sobre todo de «asociaciones de seguridad». Estos contratos bilaterales disponen de medios imperativos de coordinación entre grupos de poder en competencia e inspecciones, de manera que puede practicarse una seguridad de las expectativas de carácter no normativo, sino fundamentada puramente en términos de racionalidad instrumental sobre la transparencia de los planes y la calculabilidad de los motivos.

2) Porque Kant consideraba infranqueables los límites de la soberanía estatal concibió la asociación cosmopolita como una federación de Estados, no de ciudadanos del mundo. Eso era inconsecuente en la medida en que remitía cualquier situación jurídica, y no sólo la existente en el interior de los Estados, al derecho originario que pertenece a cada persona como «ser humano». Cada individuo tiene derecho a iguales libertades según leyes generales ("que todos disponen sobre todos $\mathrm{y}$, por consiguiente, cada cual sobre sí mismo»). Esta fundamentación en los derechos humanos del derecho en general representa a los individuos como portadores de derechos y presta a todo el ordenamiento jurídico moderno un sesgo individualista inalienable ${ }^{18}$. Pero si Kant consideraba esta garantía de la libertad - «o que el hombre debe hacer según leyes de libertad»-como «lo esencial del propósito de la paz perpetua», "esto es, las tres relaciones del derecho público, el derecho político, el derecho de gentes y el derecho cosmopolita" (Werke VI, $223 ; \mathrm{PP}, 37)$, entonces no se puede tampoco mediatizar la autonomía del ciudadano a través de la soberanía de sus Estados.

El quid del derecho cosmopolita consiste más bien en que pasando por encima de las cabezas de los sujetos colectivos del derecho internacional alcanza la posición

${ }^{16}$ Cfr. los ejemplos en Chr. Greenwood, "Gibt es ein Recht auf humanitäre Intervention?», en Europa-Archiv, 4, 1993, pp. 93-106, 94 .

17 . Habermas, Vergangenheil als Zukunf, Munich, Piper, 1993, pp. 10-44.

1. I. Habermas, "Anerkennung in demokratischen Rechtsstaat", en Charles Taylor, Mutikulturalismus und die Politik der Anerkonnung, Francfort, 1993, pp. 147-196. 
de los sujetos jurídicos individuales y fundamenta para éstos la pertenencia no mediatizada a la asociación de ciudadanos del mundo libres e iguales. Carl Schmitt ha pensado este punto de modo que según esta concepción «todo individuo es al mismo tiempo ciudadano del mundo (en el completo sentido jurídico de la palabra) y ciudadano de un Estado» ${ }^{19}$. Dado que al «Estado de la federación mundial» le incumbe la competencia de atribuir competencias (Kompetenz-Kompetenz) y que los individuos adquieren una posición directamente jurídica en esta comunidad internacional, el Estado particular se transforma «en una mera competencia de determinados hombres que desempeñan el doble papel de una función nacional y otra internacional» ${ }^{20}$. La consecuencia más importante de un derecho que trasciende la soberanía de los Estados es la responsabilidad personal por los crímenes perpetrados en el servicio del Estado y en el servicio militar de las personas individuales.

Entretanto, Kant ha sido sobrepasado por el desarrollo histórico también en este aspecto. Tras la Carta del Atlántico de agosto de $1941^{21}$, la Carta de las Naciones Unidas obligó de modo gencral a los Estados miembros al respeto y realización de los derechos humanos. La Asamblea General precisó estos derechos en diciembre de 1948 en su Declaración Universal de los Derechos Humanos y los ha desarrollado hasta hoy en numerosas resoluciones ${ }^{22}$. Las Naciones Unidas no ceden la protección de los derechos bumanos sólo a la ratificación nacional, disponen de instrumentos propios para la constatación de las violaciones de los derechos humanos. Para los derechos sociales, económicos y culturales, que están bajo la «reserva de lo posible», la Comisión de Derechos Humanos tiene órganos de supervisión y procedimientos de informes; para los derechos civiles y políticos ha introducido además proccdimientos de reclamación. Teóricamente las reclamaciones individuales (aunque no están reconocidas por todos los Estados firmantes) que ponen en mano de los ciudadanos particulares medios jurídicos contra el propio Gobierno tienen más importancia que la de las reclamaciones de los Estados. Pero hasta ahora falta un tribunal penal que examine y falle Ios casos constatados de violaciones de derechos humanos. Tampoco se ha llevado a cabo todavia la propuesta de nombrar un Alto Comisario de las Naciones Unidas para los Derechos Humanos, adoptada en la Conferencia de Viena sobre derechos humanos. Los tribunales de crímenes de guerra establccidos ad hoc según cl modelo de los tribunales militares internacionales de Nuremberg y Tokio son hasta ahora

39 En su reseña de la obra de Georges Scelle, Prócis de droit des gens, París, vol. I, 1932, vol. 2., 1934, en C. Schmitt, Die Wendung zum diskriminierenden Kriegsbegriff (1938), Berín, 1988, p. 16.

Schmitt (1988), p. 19.

" El 14 de agosto le 1941, el presidente estadounidense F, D. Roosevelt y el primer ministro W. Churchill firmaron en aun lugar del Atlántico» esa declaración de principios, que tiene el valor de ser uno de los precedentes más inmediatos de la Carta de las Naciones Unidas ( $N$. del $T$ ).

Sobre la Conferencia de Viena sobre derechos humanos, cfr. R. Wolfrum, «Die Entwicklung des internationalen Menschenrechtsschutzesm, en Europa-Archiv, 23, 1993, pp. 681-690; sobre el estatuto de los conflictivos derechos de solidaridad, efr. W. Huber, "Art. Menschenrechte/Menschenwürde», en Theologische Realenzyklopädie, Berlín-Nueva York, XXII, 1992, pp. 577-602; así como E. Riedel, "Menschenrecht der dritten Dimension", en Europäische Gruhdrechte Zeitschrift, 1989, pp. 9-21. 
excepcioncs ${ }^{23}$. Sin embargo, la Asamblea de las Nacioncs Unidas ha reconocido las directrices que sirven de base en tales juicios como «principios del derecho internacional». Por ello resulta falsa la afirmación de que los procesos contra los mandos militares, diplomáticos, funcionarios, médicos, banqueros y grandes industriales del régimen nazi sean un «único» antecedente, carente de la fuerza creadora de derecho propia del precedente ${ }^{24}$.

El punto flaco de la protección global de los derechos es por eso la falta de un poder ejecutivo que pudiera proporcionar respeto a la Declaración Universal de los Derechos Humanos mediante la injerencia en el poder soberano de los Estados nacionales. Dado que los derechos humanos deben ser aplicados en muchos casos contra los Gobiernos nacionales, debe ser revisada la prohibición de intervenir estipulada por el derecho internacional. Cuando no falta un poder estatal que funcione, como en el caso de Somalia, la organización mundial emprende su intervención sólo con el consentimiento de los Gobiernos afectados (como en Liberia y en Croacia/Bosnia) ${ }^{25}$. Sin embargo, durante la guerra del Golfo, con la resolución 688 , de abril de 1991, ha entrado no con razones jurídicas, sino de hecho, por un nuevo camino. Entonces las Naciones Unidas apelaron al derecho de intervención que según el capítulo VII de la Carta le corresponde en los casos de «amenaza de la seguridad internacional», por cuanto que, visto desde una perspectiva jurídica, tampoco esa vez intervinieron en los «asuntos internos» de un Estado soberano. Pero de facto lo hicieron, y los aliados eran bien conscientes de ello, cuando cstablecieron zonas de exclusión de vuelo sobre el espacio aéreo iraquí y emplearon fuerzas armadas terrestres en el norte de Irak para crear «zonas de protección» para los refugiados kurdos (mal utilizadas en el ínterin por Turquía), esto es, proteger a los miembros de una minoría nacional contra el propio Estado ${ }^{26}$. El ministro británico de Asuntos Exteriores habló en esa ocasión de una «ampliación de los límites de la acción internaciona ${ }^{2}{ }^{27}$.

3) La revisión de los conceptos fundamentales, que resulta necesaria en referencia al carácter cambiante de las relaciones interestatales y a las limitaciones normativas del espacio de acción de los Estados soberanos, tiene consecuencia para la concepción de la asociación de naciones y el orden cosmopolita. Las pretenciosas normas que entretanto existen lo toman en consideración; pero, como siempre, existe una gran discrepancia entre el tenor literal y el cumplimiento de esas normas. La actual situación mundial se puede comprender, en el mejor de los casos, como una situación transitoria desde el derecho internacional hacia el derecho cosmopolita. Muchos signos hablan más bien de una recaída en el nacio-

${ }^{23}$ En 1993 el Consejo de Seguridad [resolución 827 , del 25 de mayo (N. del T.)] ha creado un Tribunal con esas características para la persecución de los crímenes de guerra y contra la humanidad en la antigua Yugoslavia.

${ }^{24}$ Así se manifiesta H. Quaritsch en su epilogo a C. Schmitt, Das intemationalrechtiche Verbrechen des Angriffskieges (1945), Berlín, 1994, pp. 125-247, 236 y ss.

${ }^{25}$ Cfr. los analisis y conclusiones de Chr. Greenwood (1993).

"G Greenwood (1993) concluye: "La idea de que las Naciones Unidas pueden utilizar sus competencias de acuerdo con la Carta para intervenir por razones humanitarias en un Estado apatece ahora mucho más fuertemente cstablccidas (104).

${ }^{29}$ Citado según Greenwood (1993), 96. 
nalismo. La valoración depende en primera línea de cómo apreciemos la dinámica de las tendencias «enfrentadas». Hemos seguido la dialéctica de aquellos desarrollos cuyos inicios Kant consideró en su tiempo bajo los rótulos del pacifismo de las repúblicas, de la fuerza asociativa de los mercados globales y de la presión normativa de la esfera pública liberal. Esas tendencias se encuentran hoy en una constelación imprevisible.

Kant ya se había representado esa expansión de la asociación de Estados libres, de modo que en torno al núcleo de una vanguardia de repúblicas pacíficas se aglutinaran cada vez más Estados: «Pero si la fortuna dispone que un pueblo fuerte e ilustrado se constituya en una república [...], ésta puede constituir el centro de la asociación federativa para que otros Estados se unan a ella, asegurando [...] y extendiéndose, poco a poco, mediante otras uniones de ese tipo" (Werke VI, 211; PP, 24-25). Pero de hecho la organización mundial reúne hoy a todos los Estados bajo su techo independientemente de que estén ya constituidos republicanamente o de que respeten los derechos humanos. La unidad política del mundo encuentra su expresión en la Asamblea General de las Naciones Unidas, en la que todos los Gobiernos se encuentran representados con los mismos derechos. Hablo de «sociedad mundial» porque los sistemas de comunicación y los mercados han establecido un conjunto global; pero se debe hablar de sociedad global «estratificada», porque el mecanismo del mercado mundial vincula productividad progresiva con depauperación creciente y, en general, procesos de desarrollo con otros de subdesarrollo. La globalización escinde al mundo y lo fuerza tanto a la comunidad de riesgo como simultáneamente a la acción cooperativa.

Desde el punto de vista de la ciencia política el mundo se ha dividido desde 1917 en tres. Por supuesto que hoy las etiquetas de Primcro, Segundo y Tercer Mundo han adoptado otro significado ${ }^{28}$. El Tercer Mundo se compone hoy de territorios donde la infraestructura estatal y el monopolio de la violencia se han conformado tan débilmente (Somalia) o se han desmoronado tanto (Yugoslavia), en donde las tensiones sociales son tan fuertes y las ondas de tolerancia de la cultura política tan bajas que los poderes indirectos de tipo mafioso o fundamentalista sacuden el orden interno. Estas sociedades están amenazadas por procesos nacionales, étnicos o religiosos de descomposición. Por otro lado está el Segundo Mundo, perfilado por la herencia de la política de expansión que los Estados nacionales surgidos de la descolonización han recibido de Europa. En el interior estos Estados compensan con frecuencia relaciones inestables mediante constituciones autoritarias (por ejemplo, en la región del Golfo). Emplean la violencia militar y obedecen sólo a la lógica del equilibrio de poder. Sólo los países del Primer Mundo pueden prestarse a concertar sus intereses nacionales hasta un determinado grado con aquel punto de vista normativo que estipula el nivel de exigencia cosmopolita de las Naciones Unidas.

Como indicadores de pertenencia a ese Primer Mundo nombra R. Cooper una irrelevancia creciente de las cuestiones fronterizas y la tolerancia hacia el pluralismo en el interior; una influencia recíproca sobre los asuntos tradicionales de la política interior en las relaciones interestatales; en general, una fusión creciente

${ }^{23}$ Cfr. R. Cooper, *Gibt es eine nove Welt-Ordnung?w, en Europa-Archiv, 18, 1993, pp. 509-516. 
de la política interior y exterior; sensibilidad frente a la presión de la esfera pública liberal; el rechazo del poder militar como medio de solución de los conflictos y la juridificación de las relaciones internacionales; finalmente una preferencia por las colaboraciones que basan la seguridad en la transparencia y la confianza de las expectativas. Este mundo define, por asi decir, el meridiano de un presente en el que se fija la sincronización política de lo no sincronizado económica y culturalmente. Eso lo ignoraba Kant, que como hijo del xvil no pensaba todavía históricamente y pasaba por alto la abstracción real que lleva a cabo la organización de la comunidad internacional y que al mismo tiempo hay que tener en cuenta en sus políticas.

La política de las Naciones Unidas sólo puede considerar esta «abstracción real» trabajando por la superación de las tensiones sociales y las desigualdades económicas. Por otro lado, esto sólo se puede lograr si a pesar de la estratificación de la sociedad mundial se alcanza un consenso con respecto al menos a tres cuestiones, a saber: una conciencia histórica compartida de todos los miembros acerca de la no sincronización de las sociedades que requiere al mismo tiempo la coexistencia pacífica; un acuerdo normativo sobre los derechos humanos cuya interpretación se disputa entre los europeos, poì una parte, y los africanos y asiáticos, por otra ${ }^{29}$, y finalmente un acuerdo sobre la concepción del estado de paz al que se aspira. Kant se podría haber contentado con un conccpto negativo de paz. Esto no es sólo insatisfactorio a causa de la limitación de la guerra, sino ante todo por la circunstancia de que el origen de la guerra tiene causas sociales.

Conforme a una propuesta de Dieter y Eva Senghaas ${ }^{30}$, la complejidad de las causas de las guerras exige una concepción que concibe la paz misma con un proceso que transcurre sin violencia, pero que no se orienta sólo a la prevención de la violencia, sino al cumplimiento de los presupuestos reales de una vida en común sin tensiones de los pueblos y grupos. Las regulaciones puestas en práctica no pueden vulnerar la existencia y la autoestima de las partes ni dañar tanto los intereses vitales y sensibilidades de la justicia hasta el punto que las partes en conflicto por el agotamiento de las posibilidades de la negociación vuelvan a emplear de nuevo la violencia. Las políticas que se orientan por dicho concepto de paz recurrirán a todos los medios por debajo del umbral del uso de la fuerza militar, incluyendo la intervención humanitaria para actuar en la situación interior de los Estados formalmente soberanos con la meta de fomentar una economía y relaciones sociales soportables, la participación democrática, el Estado de derecho y la tolerancia cultural. Tales estrategias de intervención pacífica en favor de los procesos de democratización ${ }^{31}$ cuentan con que las interrelaciones entre todos los Estados los han hecho dependientes de su entorno y sensibles al poder suave de las influencias indirectas - hasta las sanciones económicas.

Con la complejidad de los fines y de las estrategias crecen también las dificultades de puesta en práctica que estorban a las potencias dirigentes para adoptar las

\footnotetext{
* Una propuesta racional para un marco de discusión se encuentra en T. Lindholm, «The Cross-Cullural Legitimacy of Human Rights», Nomegian Institute of Human Rights, 3, Oslo, 1990.

30 Dieter y Eva Senghaas, «Si vis pacem, para pacem», en Leviathan, 1992, pp. 230-247.

"E. O. Czempiel estudia esas estrategias en distintos ejemplos. Cfr. G. Schwarz, anternationale Politik und der Wandel von Regimens, Zeitschrift fü Politik, Zurich, 1989, núm. especial, pp. 55-75.
} 
iniciativas y soportar los costes. Deben ser mencionadas al menos cuatro variables, importantes en este contexto: la composición del Consejo de Scguridad, que debe actuar coordinadamente; la cultura política de los Estados, cuyos gobiernos se mueven sólo a corto plazo por políticas «desinteresadas» si se ven obligados a reaccionar a la presión normativa de la movilización de la opinión pública; la formación de órganos regionales que concedan a la organización mundial una base efectiva, $y$, finalmente, la coacción suave de una acción coordinada mundialmente que parta de la percepción de peligros globales. La amenaza de desequilibrios ecológicos, de las asimetrías en el bienestar y en el poder económico, de la gran tecnología, del tráfico de armas, especialmente la propagación de armas atómicas, biológicas y químicas, del terrorismo, de la criminalidad asociadas a las drogas, etc., es evidente. Quien a fortiori desespera de la capacidad de aprendizaje del sistema internacional debe poner su esperanza en el hecho de que la globalización de estos peligros ha unido al mundo en su conjunto a largo plazo y de modo objetivo en una comunidad involuntaria de riesgo.

\section{IV}

Una reformulación adaptada a los tiempos de la idea kantiana de una pacificación cosmopolita del estado de naturaleza entre los Estados inspira, de un lado, los enérgicos esfuerzos de reforma de las Naciones Unidas y, en general, de constitución de capacidades de acción supranacionales en las diferentes regiones de la tierra. Se trata ahí de la mejora del marco institucional de una política de derechos humanos que ha tomado impulso desde la presidencia de Jimmy Carter, pero que también ha sufrido sensibles reveses, 1). Esta política ha provocado, de otro lado, una fuerte oposición al plan que ve en el intento de realización internacional de los derechos humanos una moralización autodestructiva de la política. Los contraargumentos se apoyan en un concepto de los derechos que diferencia la esfera jurídica de la moral, 2).

1) La retórica del universalismo contra el que se dirige esta crítica encuentra su expresión en las propuestas sobre la necesidad de que las Naciones Unidas se constituyan en una «democracia cosmopolita». Las propuestas de reforma se concentran en tres puntos: en el cstablecimiento de un parlamento mundial, cn la construcción de una justicia mundial y en la obligada reorganización del Consejo de Seguridad ${ }^{32}$.

A las Naciones Unidas se le sigue concibiendo como un «congreso permanente de Estados". Si debe perder ese carácter de asamblea de las delegaciones gubernamentales, la Asamblea General debe transformarse en una especie de Consejo Federal y sus competencias dividirse en dos cámaras. En este parlamento no estarían representados los pueblos a través de sus Gobiernos, sino por medio de representantes elegidos por la totalidad de los ciudadanos del mundo. Los países que se negaran a la elección de los diputados según criterios democráticos (respetando

Sigo a D. Archibugi, "From the United Nations to Cosmopolitan Democracy», en Archibugi y Held (1995), pp. 12l-162. 
sus minorías nacionales) serían representados en el ínterin por organizaciones no gubernamentales que el propio parlamento mundial dispusiera como representantes de las poblaciones reprimidas.

Al Tribunal Internacional de Justicia de La Haya le falta competencia para formular acusaciones, no puede dictar sentencias vinculantes y debe limitarse a las funciones de tribunal arbitral. Su jurisdicción está limitada por lo demás a las relaciones entre los Estados y no se extiende a los conflictos entre personas individuales o entre ciudadanos particulares y sus Gobiernos. En todos estos aspectos deberían ampliarse las competencias del Tribunal de Justicia en la línea de las propuestas que Hans Kelsen había elaborado hace medio siglo ${ }^{33}$. La justicia penal internacional, que hasta ahora tan sólo ba sido establecida ad hoc para procesos singulares de crímenes de guerra, debería institucionalizarse de manera permanente.

El Consejo de Seguridad fue concebido como contrapeso de la Asamblea General, configurada igualitariamente; debía reflejar las relaciones fácticas de poder en el mundo. Después de cinco décadas este principio racional precisa de ciertas adaptaciones a la modificada situación del mundo que no deberían agotarse en la ampliación de la representación de los Estados nacionales más influyentes (como, por ejemplo, mediante la incorporación de Alemania y Japón como miembros permanentes). En vez de eso se propone que junto a las potencias mundiales (como los Estados Unidos), las organizaciones regionales (como la Unión Europea) mantengan un voto privilegiado. Por lo demás, la coacción de la unanimidad entre los miembros permanentes debería sustituirse por la apropiada regla de la mayoría. En general, el Consejo de Seguridad podría ser configurado según el modelo de Consejo de Ministros de Bruselas con una capacidad de acción ejecutiva. Por lo demás, los Estados coordinarán sólo su política exterior tradicional a los imperativos de una política interna mundial si la organización mundial puede emplear las fuerzas armadas bajo mando propio y ejercer funciones policiales.

Estas reflexiones son convencionales en tanto que se orientan a las partes organizativas de las constituciones nacionales. La puesta en práctica de un derecho cosmopolita explicado conceptualmente requiere, obviamente, algo más que imaginación institucional. Pero en cualquier caso permanece el universalismo moral, que guió a Kant en su proyecto, como intuición reguladora. Contra esta autocomprensión práctico-moral de la modernidad ${ }^{34}$ se dirige, sin embargo, un argumento que en Alemania, desde la critica hegeliana a la moral kantiana de la humanidad, ha tenido una historia de enorme eficacia y ha dejado hasta hoy profundas huellas. Su formulación más aguda y fundamentación en parte ingeniosa y en parte confusa es la realizada por Carl Schmitt.

Schmitt reduce la sentencia «el que dice humanidad pretende engañar» a la contundente fórmula «humanidad, bestialidad». El «engaño del humanismo» tiene sus raíces en la hipocresía de un pacifismo jurídico que bajo la etiqueta de paz y derecho internacional quiere hacer "guerras justas»: "Cuando el Estado combate a su enemigo en nombre de la humanidad entonces no se trata de una guerra

${ }^{33}$ Hans Kelscn, Peace through Law, Chapel Hill, 1994.

${ }^{34}$ J. Habermas, Der philosophische Diskur der Modeme, Francfort, 1985, pp. 390 y ss. [Hay trad. cast.: El discurso filosófico de la modernidad, Madrid, 1989, pp. $397-433$ ( $N$, del T.)]. 
de la humanidad, sino de una guerra en la que un determinado Estado busca apropiarse un concepto universal frente a su adversario bélico, del mismo modo que se puede abusar de la paz, la justicia, el progreso y la civilización con el fin de reivindicarlos para uno mismo negándoselo al enemigo. La "humanidad" es un instrumento ideológico especialmente manipulable [...] ${ }^{35}$.

Este argumento, dirigido todavía en 1932 contra los Estados Unidos y las potencias vencedoras de Versalles, lo extiende Schmitt más tarde a las acciones de la Sociedad de Naciones y de las Naciones Unidas. La política de una organización mundial que se inspira cn la idea kantiana de la paz perpetua y se dirige a la construcción de un orden cosmopolita pertenece, según su concepción, a la misma lógica: el panintervencionismo conduce a la pancriminalización, y con ello a la perversión del objetivo al que debe servir ${ }^{36}$.

2) Antes de introducirme en el contexto especial de esta reflexión quiero tratar el argumento de modo general y desbrozar su núcleo problemático. Los dos enunciados decisivos son: que la política de los derechos humanos conduce a guerras que -ocultas como acciones de policía- adoptan un carácter moral, y que esta moralización marca al adversario como enemigo, de modo que csta criminalización abre las puertas de par en par a la inhumanidad: "Conocemos la ley secreta de este vocabulario y sabemos que la guerra más horrible se rcaliza hoy en nombre de la paz [...] y la inhumanidad más atroz en nombre de la humanidad ${ }^{37}$. Ambos enunciados parciales se fundamentan con la ayuda de dos premisas: a) la política de los derechos humanos sirve a la realización de normas que son parte de una moral universalista; $b$ ) dado que los juicios morales pertenecen al código de «bueno» y «malo», la valoración moral negativa de un adversario bélico (o de un oponente político) destruye la delimitación institucionalizada jurídicamente de la lucha militar (o de la controversia política). Mientras que la primera premisa es falsa, la segunda sugiere un falso presupuesto en conexión con una política de los derechos humanos.

a) Los dercchos humanos, en el sentido moderno, remiten tanto a la declaración de derechos de Virginia y a la declaración de independencia de 1776 americana como a la Déclaration des droits de l'homme et du citoyen de 1789. Estas declaraciones están inspiradas por la filosofía política del derecho racional, en especial por Locke y Rousseau. Pero no es ninguna casualidad que los derechos humanos adoptaran ya en el contexto de aquellas primeras constituciones una forma concreta, a saber, como dcrechos fundamentales que han de ser garantizados en el marco de un ordenamiento jurídico nacional. Sin embargo, tienen, tal como parece, un doble carácter: como normas constitucionales gozan de validez positiva,

${ }^{35}$ C. Schmith, Der Begriff des Politiscien (1932), Berlin, 1963, p. 55 [hay trad. cast.: El concepto de lo político, Madrid, Alianza, 1991, p. 83 ( $N$. del T. J. El mismo argumento se encuentra en Isensee (1995): «Desde que hay intervenciones han servido a la ideología, a los principios confesionales del siglo xvi y xwil, a los monárquicos, a los jacobinos, a los humanitarios y a los de la revolución socialista mundial. Ahora, derechos humanos y democracia están en la misma fila. Fn la larga historia de la intervención la ideología servia para cnnoblecer los intereses de poder de los que intervienen y proporcionar efectividad a la consagración de la legitimación» (429).

${ }^{35}$ C. Schmitt, Glossarium (1947-1951), Berlin, 1991, p. 76.

${ }^{37}$ C. Schmit1 (1963), p. 94 [trad. cast.: El concepto de lo politico, op. cit, p. 121 (N. del T.)]. 
pero como derechos que les corresponden a cada persona como ser humano se les adscribe al mismo tiempo una validez suprapositiva.

En la discusión filosófica esta ambivalencia ha provocado resquemores ${ }^{38}$. Según una de las concepciones, los derechos humanos adoptan un estatuto entre derecho moral y positivo; según otra, deben poder presentarse con el mismo contenido en la forma tanto de derechos morales como de derechos jurídicos - «como derecho preestatalmente válido, aunque no por eso ya vigente»- ${ }^{39}$. Los derechos humanos «no son propiamente protegidos o negados, pero tampoco garantizados o despreciados». Estas fórmulas confusas sugieren que el constituyente tan sólo reviste las normas morales, siempre dadas con la forma de derecho positivo. Con esta remisión a la clásica distinción entre derecho natural y legal se colocan las agujas de modo falso, según mi concepciôn. El concepto de derechos humanos no tiene un origen moral, sino una acuñación espccífica del concepto moderno de derechos subjetivos, esto es, de una terminología jurídica. Los derechos humanos tienen originariamente una naturaleza jurídica. Lo que le presta la apariencia de derechos morales no es su contenido, y con mayor motivo tampoco su estructura, sino su sentido de validez, que trasciende los ordenamientos jurídicos de los Estados nacionales.

Los textos constitucionales históricos se refieren a los derechos «innatos»y tienen a menudo la forma festiva de «declaraciones»: ambas fórmulas nos previenen sin duda, como hoy diriamos, de un malentendido positivista y expresan que los derechos humanos «no están a disposición» del legislador correspondiente ${ }^{40}$. Pero esta reserva retórica no puede proteger a los derechos fundamentales del destino de todo derecho positivo: también pueden ser cambiados o derogados, por ejemplo por un cambio de régimen. Como parte consitutiva de un ordenamiento jurídico democrático gozan, como el resto de normas jurídicas, claro está, de «validez» en el doble sentido de que valen no sólo fácticamente, esto es, que son ejecutadas gracias al poder estatal de sanción, sino que reclaman también legitimidad, esto es, deben ser capaces de una fundamentación racional. Bajo este aspecto de la fundamentación los derechos humanos tiene ahora de hecho un estatus destacable.

Los derechos fundamentales gozan, en cuanto normas constitucionales, de una preferencia que se muestra, entre otras cosas, en que como tales son constitutivos para el ordenamiento jurídico y estipulan un marco en el interior del cual debe moverse la legislación normal. Pero de la totalidad de las normas constitucionales destacan los derechos fundamentales. Los derechos fundamentales liberales y sociales tienen la forma de normas generales que se dirigen a los ciudadanos en su cualidad de «seres humanos» (y no sólo miembros de un Estado). Incluso aunque los derechos humanos se hacen efectivos en el marco de un ordenamiento jurídico nacional, fundamentan en ese marco de validez derechos para todas las personas, no sólo para los ciudadanos. Cuanto más se exprime el contenido de derechos

St. Shue y S. Hurlcy (cds.), On Human Rights, Nueva York, 1993.

" O. Hoffe, «Die Menschenrechte als Legitimation und kritischer Maßtah der Demokratie», en J. Schwardtländer (ed.), Menschenrechte und Demokratie, Strapburg, 1981, p. 250. Cfr. también del mismo autor, Politische Gerechigkeit, Francfort, 1987.

* S. König, Zur Begrinułung der Menschenrechle: Hobbes-Lacke-Kant, Freiburg, 1994, pp. 26 y ss. 
humanos existente en la Ley Fundamental tanto más se asimila el estatuto jurídico de los no-ciudadanos que viven en la República Federal con el de los ciudadanos ${ }^{41}$. Estos derechos fundamentales comparten con las normas morales esa validez universal referida a los seres humanos en cuanto tales. Como se muestra en la actual controversia sobre el derecho electoral de los extranjeros, esto tambićn vale en determinados aspectos para los derechos fundamentales políticos. Esto remite a un segundo aspecto, aún más importante. Los derechos humanos están provistos de aquella validez universal porque pueden ser fundamentados exclusivamente desde el punto de vista moral. También otras normas jurídicas son fundamentadas ciertamente con la ayuda de argumentos morales, pero en general confluye en la fundamentación puntos de vista ético-políticos y pragmáticos que hacen referencia a formas de vida concretas de una comunidad histórica de derecho o a objetivos concretos de determinadas políticas. Los derechos fundamentales regulan, por cl contrario, materias que por su generalidad los argumentos morales bastan para su fundamentación. Estos son argumentos que fundamentan por qué la garantia de tales reglas se encuentra en los intereses iguales de todas las personas en su calidad de personas en general, por qué tales reglas son, pues, buenas en igual medida para cualquiera.

Este modo de fundamentación no despoja en absoluto a los derechos fundamentales de su cualidad jurídica, ni hace de ellos normas morales. Las normas juridicas -en el sentido moderno del derecho positivo- mantienen su juridicidad, $\mathrm{y}$ de igual modo su pretensión de legitimidad puede ser fundamentada con la ayuda de cualquier clase de razones, pues ese carácter se debe a su estructura no a su contenido. $Y$ según su estructura, los derechos humanos son derechos subjetivos reclamables que tienen precisamente el sentido de descargar a las personas jurídicas de los preceptos morales bien determinados, concediendo a los actores espacios de juego legales para las acciones guiadas por sus propias preferencias. Mientras los derechos morales se basan en deberes, que vinculan a las voluntades libres de las personas autónomas, los deberes jurídicos se derivan sólo como consecuencia de la autorización para la acción arbitraria, esto es, de la delimitación legal de estas libertades subjetivas ${ }^{42}$.

Esta preeminencia conceptual de los derechos frente a los deberes se deriva de la estructura del moderno derecho coactivo puesta de relieve, en primer lugar, por Hobbes. Hobbes introdujo un cambio de perspectiva frente al derecho premoderno, todavía pensado desde la perspectiva religiosa o metafísica ${ }^{43}$. A diferencia de la moral deontólogica que fundamenta deberes, el derecho sirve para la protección del libre arbitrio del individuo de acuerdo con el principio de que está

${ }^{41}$ El contenido de derechos humanos de los derechos políticos de participación implica, de todos modos, que cada persona ticne cl derccho de pertenecer a una comunidad política en calidad de ciudadano.

${ }^{42}$ Cfr. cl análisis de la estructura de los derechos humanos de H. A. Bedau, «International Human Rights", en T. Regan y D. van de Weer (eds.), And Justice for All, Totowa, 1983, p. 297, con referencia a Henry Shue, «El énfasis sobre los deberes está pensado para evitar dejar la defersa de los derechos humanos en un vacio, carente de cualquier significado moral para la conducta específica de otros. Pero no se pretende que los deberes expliquen o generen dercchos; si acaso se supone que los derechos han de explicar y generar los deberesis.

König (1994), pp. 84 y ss. 
permitido todo lo que no está explícitamente prohibido según leyes generales limitadoras de la libertad. Si los derechos stibjetivos derivados deben ser legítimos, la generalidad de estas leyes deben, sin embargo, satisfacer el punto de vista moral de la justicia. El concepto de derecho subjetivo que protege una esfera de libre arbitrio tiene para el derecho moderno en su conjunto una fuerza estructurante. Por eso Kant concibe el derecho como wel conjunto de condiciones bajo las cuales el arbitrio de uno puede coexistir con el arbitrio del otro según una ley universal de libertad» (Rechtslehre, Werke IV, 337; MC, 39). Todos los derechos humanos especiales tienen según Kant su fundamento en el único derecho originario a iguales libertades subjetivas: «La libertad (la independencia con respecto al arbitrio constrictivo de otro), en la medida en que puede coexistir con la libertad de cualquier otro según una ley universal, es este derecho único, originario, que corresponde a todo hombre en virtud de su humanidad" (Rechtslehre, Werke IV, 345; MC, 48-49).

En Kant los derechos humanos encuentran de modo consecuente su lugar en la teoría del derecho y sólo ahí. Como otros derechos subjetivos, tienen -y ellos con mayor motivo- un contenido moral. Pero a pesar de este contenido, los derechos humanos pertenecen según su estructura a un orden de derecho positivo y coercitivo que fundamenta pretensiones jurídicas subjetivas reclamables. En cuanto tales, forma parte del sentido de los derechos humanos que requieran el estatus de derechos fundamentales que deben ser garantizados en el marco de un ordenamiento jurídico existente, sea nacional, internacional o global. De todas maneras, se da entender una cierta confusión con los derechos morales, porque estos derechos, a pesar de su pretensión de validez universal, sólo han podido tener hasta ahora una forma positiva no ambigua en los ordenamientos jurídicos nacionales de los Estados democráticos. Manticnen además una débil validez scgún cl derccho internacional y esperan aún su instítucionalización en el marco de un orden cosmopolita tan sólo en proceso de formación.

b) $\mathrm{Si}$, en cambio, esta primera premisa que los derechos humanos son originariamente derechos morales - fuera falsa, se quita la base al primero de los enunciados parciales - el enunciado de que la realización global de los derechos humanos conduce a una lógica moralista y por eso a intervenciones que tan sólo se camuflan como acciones de policía-. Al mismo tiempo se ve sacudido el segundo enunciado de que una política intervencionista de los derechos humanos degenera ncccsariamente en una «lucha contra el mal». Este enunciado sugiere el falso presupuesto de que el derecho internacional clásico, perfilado para las guerras limitadas, basta para orientar los enfrentamientos militares hacia vías «civilizadas». Aun cuando este presupuesto fuese adecuado, las acciones de policía de una organización mundial capacitada para la acción y legitimada democráticamente serviria al nombre de una expansión civil de los conflictos internacionales más aún que tales guerras limitadas. Pues cl establecimiento de un orden cosmopolita significa quc las violaciones de derechos humanos no son juzgadas y combatidas directamente desde el punto de vista moral, sino como acciones criminales en el marco de un ordenamiento jurídico estatal —según procedimientos jurídicos institucionalizados. Precisamente la juridificación del estado de naturaleza entre los Estados 
protege de la desdiferenciación moral del derecho y garantiza a los inculpados, también a los casos actualmente relevantes de criminales de guerra y crimenes contra la humanidad, la completa protección jurídica, esto es, protección ante la discriminación moral ${ }^{44}$.

\section{V}

Quiero desarrollar metacríticamente este argumento en discusión con las objeciones de Carl Schmitt. Antes debo introducirme en el contexto de estas objeciones, porque Schmitt relaciona diferentes niveles de la argumentación no siempre de modo transparente. Schmitt se ocupa, aunque sobre todo en referencia al concepto discriminatorio de guerra, de la crítica a un derecho internacional que traspasa la soberania de los Estados individuales. Con esto parece ganar su crítica un enfoque claro y jurídicamente limitado. La crítica se dirige especialmente contra la penạlización de la guerra ofensiva prescrita en la Carta de las Naciones Unidas y contra la detención de personas individuales por algún tipo de crímenes de guerras que el derecho internacional válido hasta la Primera Guerra Mundial no conocía. Pero para esta explicación jurídica, inofensiva en sí misma, Schmitt echa mano de reflexiones políticas y fundamentaciones metafísicas. Debemos por eso deshojar primero la teoría en su trasfondo, 1), para introducirnos en el núcleo de crítica moral del argumento, 2).

1) At face value la argumentación jurídica se dirige a la civilización de la guerra por medio del derecho internacional, a); esa argumentación se relaciona con una argumentación política que sólo parece tratar del mantenimiento de un orden internacional acreditado, $b$ ).

a) Schmitt rechaza la diferenciación entre guerra ofensiva y defensiva no por razones pragmáticas, que son difíciles de hacer operativas. La razón jurídica es, más bien, que un concepto moralmente neutral de guerra que también excluya la responsabilidad personal por una guerra punitiva es conciliable con la soberanía del sujeto del derccho internacional, pues el its ad bellum, esto es, el derecho a iniciar una gucrra en cualquier momento por cualquier razón es constitutiva de la soberanía de un Estado. En este plano de la argumentación Schmitt aún no aborda, como muestra el escrito en cuestión ${ }^{45}$, las desastrosas consecuencias del universalismo moral, sino la limitación de las guerras. Sólo la praxis de la no discriminación de la guerra debe poder limitar las acciones bélicas y proteger del mal de una guerra total, que Schmitt analizó con gran claridad ya antes de la Segunda Guerra Mundial ${ }^{46}$.

Schmitt presenta la exigencia de volver al statu quo ante de la guerra limitada sólo como la alternativa más realista a la pacificación por medio del derecho internacional del estado de naturaleza entre los Estados; la eliminación es, en com-

\footnotetext{
4. Sobre la diferenciación entre ética, derecho y moral, cfr. R. Forsi, Kontexte der Gerechtigkeit, Francfort, 1994.

4 C. Schmitt (1994).

4s C. Schmitt (1963) y (1988).
} 
paración con la civilización de la guerra, un objetivo ciertamente amplio y además, tal como parece, utópico. Puede, sin embargo, dudarse del «realismo» de esta propuesta con buenas razones empíricas. La mera apelación a un derecho internacional que procede de las guerras de religión como una de las grandes prestaciones del racionalismo occidental no señala aún un camino transitable pragmáticamente para la reedificación del mundo clásico moderno del equilibrio de las potencias. Pues en su forma clásica el derecho internacional rechaza explícitamente el hecho de la guerra total desencadenado en el siglo xx. Detrás del intento de no limitar la guerra se encuentran importantes fuerzas propulsoras, que siempre podrían ser domesticadas a través más bien de sanciones e intervenciones de una comunidad internacional organizada que a través de un llamamiento sin consecuencias jurídicas a la prudencia de los Gobiernos soberanos, pues una vuelta al orden del clásico derecho internacional restituiría la plena libertad de acción a aquellos actores colectivos que deben cambiar su comportamiento incivilizado. La debilidad del argumento es la primera indicación de que la argumentación jurídica forma sólo una fachada detrás de la cual se ocultan consideraciones de otro tipo.

Después de la Segunda Guerra Mundial, C. Schmitt podía salvar la consistencia de una argumentación procedimental puramente jurídica sólo poniendo entre paréntesis los crimenes de masas perpetrados durante el período nazi como una categoría especial para preservar al menos de este modo la apariencia de neutralidad moral de la guerra como tal. En 1945 Schmitt diferencia, consecuentemente (en un informe redactado en favor de Friedrich Flick, imputado en Nuremberg), entre crímenes de guerra y aquellas atrocities que como «expresión característica de una determinada mentalidad inhumana» exceden a la capacidad humana: «La orden de un superior no puede justificar o disculpar tal crimen atrozs ${ }^{47}$. El sentido puramente táctico dentro del proceso de esta distinción que Schmitt propone como abogado emana con claridad brutal de los textos escritos pocos años más tarde en su diario. En cste «Glossarium» se ve con claridad que Schmitt quiere ver descriminalizada no sólo la guerra ofensiva, sino también la quiebra civilizatoria del aniquilamiento de los judíos. Así, pregunta: «iQué es un "crimen contra la humanidad"? aHay crímenes contra el amor?» $\mathrm{Y}$ duda de que se trate de un tipo delictivo jurídico porque el «objeto de protección y de ataque» de tales crímenes no puede ser descrito con suficiente precisión: "Genocidio, asesinato de pueblos, concepto tranquilizador; yo he vivido un ejemplo en mi propio cuerpo: la expulsión del funcionariado alemán-prusiano.» Esta delicada comprensión del genocidio conduce a Schmitt a una conclusión que va más allá: "Crímenes contra la humanidad" es sólo la cláusula más general de todas las cláusulas generales para el exterminio del enemigo.» En otro lugar afirma luego: "Hay crimenes contra la humanidad y crímenes por la humanidad. Los crímenes contra la humanidad fueron perpetrados por los alemanes. Los crímenes por la humanidad fueron perpetrados contra los alemanes ${ }^{48}$.

Se trata aquí claramente de otro argumento. La realización del derecho cosmopolita con el resultado de un concepto discriminatorio de guerra no se concibe

\footnotetext{
"Schmitt (1994), 19.

C. Schmitt, Glosariam (1947-1951), Berlín, 1991, pp. 113, 265, 146, $2 \times 2$.
} 
más sólo como la falsa reacción a la evolución hacia la guerra civil, sino como su causa. La guerra total es la forma de expresión contemporánea de la «guerra justa» en la que desemboca forzosamente la política intervencionista de los derechos humanos: «Decisivo es que a la totalidad de la guerra pertenece, ante todo, su justicia» ${ }^{49}$. Con eso el universalismo moral adopta el papel de explanandum y la argumentación se desvía del plano jurídico al moral. La remisión al derecho internacional clásico en Schmitt parece en primer lugar referido a la evitación de la guerra total. Pero no es seguro una vez más si ha temido la total pérdida de limitaciones de la guerra, esto es, el caracter inhumano de la guerra visto como mal propio, o antes bien la desvalorización de la guerra como tal. En cualquier caso, en un corolario de 1938 a El concepto de lo político, Schmitt describe la extensión totalitaria de la guerra a ámbitos no militares, de tal modo que atribuye a la guerra total una utilidad higiénica para el pueblo: «El paso más allá de lo puramente militar no representa sólo una expansión cuantitativa, sino también un incremento cualitativo. Por eso (la guerra total) no supone una atenuaciọn sino una intensificación de la hostilidad. La mera posibilidad de ese incremento de intensidad hace que también los conceptos de amigo y enemigo se transformen de nuevo en políticos y que, incluso alli donde su carácter político había palidecido por completo, se liberen de la esfera de las formas de hablar privadas $y$ psicologicas» 50 .

b) Si, en cambio, la pacificación de la descarrilada guerra totalitaria no debía estar en el corazón del empedernido adversario del pacifismo, podría tratarse de algo distinto: de la preservación de un orden internacional en el que las guerras en general todavía puedan ser emprendidas y los conflictos solucionados por esta vía. La praxis de la no-discriminación de la guerra mantiene intacto un mecanismo ordenador de la autoafirmación nacional ilimitada. El mal a evitar no es la guerra total, sino la destrucción de la esfera de lo político que se basa en la separación clásica de la política interior y exterior. Esto lo fundamenta Schmitt en su propia teoría de lo político. Según la cual, la política interior pacificada jurídicamente debe ser complementada por una política exterior belicista permitida por el derecho internacional, porque el Estado monopolizador de la violencia puede mantener el derecho y el orden contra la fuerza virulenta de los enemigos subversivos internos en tanto que guarde y regenere su sustancia politica en la lucha contra los enemigos exteriores. Esta sustancia sólo debe poder renovarse por medio de la disposición a matar y ser muertos, porque lo político mismo está referido en su esencia a la "posibilidad real del asesinato físico». Lo «político» es la capacidad y la voluntad de un pueblo a reconocer al enemigo y a afirmarse contra «la negación de la propia existencia» a través «de la alteridad del extraños 51 .

Estas grotescas reflexiones sobre la esencia de lo politico nos deben interesar aquí sólo por su posición argumentativa. Esta carga vitalista del concepto de lo político es el trasfondo para la afirmación de que la fuerza creativa de lo político debe transformarse en una fuerza destructiva tan pronto como la salvaje arena

\footnotetext{
Schmitt (1988), I.

${ }^{30}$ Schmitt (1963), p. 110 [trad. cast.: El concepto de lo politico, op. cit, p. 139 (N. del T.)].

st Schmitt (1963), p. 27 [trad. cast.: Et concepto de io politico, op. cit, p. 57 (N. del T.].
} 
internacional del «poder conquistador» se cierre a ella. La realización global de los derechos humanos y de la democracia, que debe favorecer la paz mundial, tendría el efecto imprevisto de que la guerra - mantenida hasta ahora «según los cánones» o controlada por medio del derecho internacional-sobrepase sus propios límites. Sin aliviaderos en el coto libre de caza debería inundar los ámbitos civiles de la vida, autónomamente desarrollados, de las sociedades modernas, esto es, eliminar la complejidad de sociedades internamente diferenciadas. Esta advertencia ante las consecuencias catastróficas de una eliminación iusirenista de la guerra se explica desde una metafísica que en el mejor de los casos podría evocar - de una manera típica en aquel momento- la estética entretanto algo marchita de las Tempestades de acero ${ }^{52}$.

2) Se puede, claro está, eliminar y especificar de esta filosofía belicista un punto de vista. Según la concepción schmittiana, detrás de la kguerra contra la guerra» fundamentada ideológicamente (que transforma una lucha militar limitada temporal y socialmente entre «unidades organizadas de pueblos» en un estado endémico de guerra civil paramilitar) está el universalismo de la moral de la humanidad concebida por Kant.

Todo habla a favor de que Carl Schmitt no hubiera reaccionado frente a las intervenciones de mantenimiento o de creación de la guerra de manera diferente a la de Hans Magnus Fnzensberger: «La retórica del universalismo es específica de Occidente. Los postulados que se establecen con ella pretenden ser aplicables a todos sin excepción ni discriminación. El universalismo no conoce diferencias por la proximidad y la lejanía; es incondicional y abstracto [...] Pero dado que todas nuestras posibilidades de actuación son finitas, la distancia entre pretensión y realidad es cada vez mayor. Pronto se sobrepasa la frontera de la hipocresía objetiva; sólo entonces el universalismo deviene en una trampa morals ${ }^{53}$. Son, pues, las falsas abstracciones de la moral de la humanidad las que nos sostienen en un autoengaño y nos conducen a un excesivo autocsfuerzo hipócrita. Tanto Enzensberger como Arnold Gehlen ${ }^{54}$ definen antropológicamente los límites sobre los que se erige esa moral en términos espaciales de proximidad y lejanía: un

${ }^{2}$ El autor alude aquí a la novela de Ernst Jünger titulada In Stahlgewittern y cuya primera edición aparcció en 1920 (trad. cast.: Tempestades de acero, Barcelona, Tusquets, 1993). Algunas reflexiones do Jünger, con un carácter más bien metapolítico, sobre la cuestión de la guerra pueden encontrarse en la siguiente recopilación de sus ensayos: La paz, Barcelona, Tusquets, 1996 (N. del T.).

$\$$ H. M. Enzensberger, Aussichten auf den Bügerkneg, Francfort, 1993, pp. 73 y ss. [Hay trad. cast.: Perspectivas de guerra civil, Barcclona, Anagrama, 1994, p. 60 (N. del T.)]. Al respecto, cfr. A. Honneth, «Universalismus als moralische Falle? " en Merkur, 546/47, 1994, pp. 867-883. Enzensberger se apoya aquí no sólo en una descripción altamente selectiva de la situación internacional que omite la soprendente expansión de las formas democráticas de Estado en Latinoamérica, África y Europa del Fste (cfr. E. O. Crompiel, Weltpolitik im Umbruch, Munich, 1993, pp. 107 y ss.). Convierte también con constantes antropológicas la compleja conexión entre la expansión fundamentalista de los conflictos potenciales internos, por un lado, y las desprivatizaciones sociales y la falta de tradiciones liberales, por otro. Precisamente el concepto ampliado de paz sugiere estrategias profilácticas y pacíficas y recuerda las limitacioncs pragmáticas a los que sufren las intervenciones humanitarias (como muestra cl ejemplo de Somalia y la situación totalmente diferente de la antigua Yugoslavia). Sobre la casuística de los diferentes tipos de intervención, cfr. D. Senghaas (1994), pp. 185 y ss.

${ }_{54}$ A. Gehten, Moral und Hypermoral. Eine pluralistische Ethik, Francfort, 1969. 
ser que está tallado do madera tan torcida funciona moralmente sólo en el ámbito próximo accesible visualmente.

Cuando Carl Schmitt habla de hipocresía abriga más bien el propósito de la crítica hegeliana a Kant. Dota a su despectiva sentencia «Humanidad, bestialidad» de un ambiguo comentario que a primera vista bien podría proceder de Horkheimer: «Decimos "cementerio central de la ciudad" y omitimos con tacto "matadero". Pero el degollar se comprende de por sí y sería inhumano, incluso bestial, pronunciar la palabra degollar» ${ }^{55}$. EI aforismo es ambiguo en la medida en que parece dirigirse en primer lugar, de modo crítico-ideológico, contra el glorioso rendimiento abstracto de los conceptos generales platónicos con los que a menudo ocultamos la cara oscura de una civilización de vencedores, es decir, el sufrimiento de sus víctimas marginalizadas. Esta interpretación reclamaría, sin embargo, una clase de respeto igualitario y compasión universal que daría validez al combatido universalismo moral. Lo que el antihumanismo de Schmitt (con el de Hegel, de Mussolini y Lenin) ${ }^{56}$ quiere hacer valer no es la res degollada, sino el degüello, el tajo del carnicero de los pueblos de Hegel, el «honor de la guerras, pues más adelante afirma: "La humanidad no puede hacer una guerra [...]. El concepto de humanidad excluye el concepto de enemigos ${ }^{57}$. Según Carl Schmitt es, pues, del orden natural de lo político de donde la moral de la humanidad abstrae la presunta distinción inevitable entre amigo y enemigo. Porque subsume las relaciones «políticas» bajo los conceptos de «bueno» y «malo», hace también del adversario bélico ael horror inhumano que no sólo hay que rechazar, sino que hay que aniquilar definitivamente» ${ }^{58}$. Y porque el concepto discriminatorio de guerra se remite al universalismo de los derechos humanos se produce finalmente la infección del derecho internacional por la moral, que explica la inhumanidad de las modernas guerras perpetradas «en nombre de la humanidad» y de las guerras civiles.

Este argumento de crítica moral ha tenido una historia de enorme eficacia, también independiente del contexto en el que se encontraba Carl Schmitt. Pues una opinión correcta se entrelaza con un error fatal nutrido del concepto de lo político como relación amigo-enemigo. El elemento verdadero consiste en que una moralización directa del derecho y la política sobrepasa de hecho aquellas zonas de protección que queremos saber garantizadas para las personas jurídicas por buenas razones, esto es, por razones morales. Pero son erróneas las premisas de que esta moralización tan sólo puede ser evitada si la política internacional es despojada de derecho y el derecho de moral. Bajo las premisas del Estado de derecho y de la democracia ambas son falsas: la idea de Estado de derecho fomenta que la sustancia del poder del Estado sea canalizada tanto hacia dentro como hacia fuera mediante el derecho legítimo; y la legitimación democrática del derecho debe garantizar que el derecho sea armonizable con los principios morales reconocidos. El derecho cosmopolita es una consecuencia de la idea de Estado

${ }^{55}$ C. Schmitt, Glossarium (1947-1951), Berlín, 1991, p. 259.

Schmitt (1991), p. 229.

"Schmitt (1963), pp. 54 y ss. [trad. cast.: El concepto de lo poitico, op. cit., p. 83 (N. del T.)].

Sh Schmitt (1963), p. 37 [trad. cast.: El concepto de lo político, op, cil., p. $66(N$, del $T$.)]. 
de derecho. Con el se produce una simetría entre la juridificación de las relaciones sociales y políticas aquende y allende las fronteras estatales.

De modo instructivo Carl Schmitt resulta inconsecuente cuando mantiene la asimetría entre una situación jurídica pacificada hacia dentro y un belicismo hacia fucra. Porque se imagina que la paz jurídica en el interior de los Estados, sólo como una latente confrontación entre los órganos estatales y sus enemigos tenidos represivamente en jaque, otorga a los ostentadores del poder político el derecho de declarar a los representantes de la oposición enemigos internos (una práctica que, por cierto, ha dejado sus huellas en la República Federal de Alemania) ${ }^{59}$. A diferencia del Estado democrático constitucional, donde los tribunales independientes y los ciudadanos en su conjunto (activados en los casos extremos mediante la desobediencia civil) deciden sobre cuestiones sensibles del comportamiento anticonstitucional, Carl Schmitt deja al arbitrio de los que tienen el poder criminalizar a los adversarios políticos como enemigos de una guerra civil. Porque en esta zona límite de las relaciones internas se relajan los controles del Estado de derecho, el efecto que Carl Schmitt teme como consecuencia de una pacificación de las relaciones interestatales es la introducción de categorías morales en las acciones políticas protegidas jurídicamente y la estilización del adversario como agente del mal. Pero es inconsecuente exigir que las relaciones internacionales estên exentas de regulaciones análogas a las del Estado de derecho.

De hecho se ha efectuado en la escena internacional una moralización directa de la política tan perniciosa como el enfrentamiento del Gobierno con sus enemigos internos -que Carl Schmitt irónicamente admite porque localiza los daños en el lugar equivocado-. Pcro en ambos casos el daño proviene de que la acción política o estatal protegida se ha codificado de un modo doblemente falso: primero se ha moralizado, esto es, se ha enjuiciado según criterios de «bueno» y «malo», luego se ha criminalizado, esto es, se ha juzgado según criterios de «lícito» e «ilícito» sin que se haya cumplido el momento decisivo, que Schmitt suprime, de los presupuestos jurídicos para una instancia judicial imparcial y una ejecución de la pena neutral. La política de derechos humanos de una organización mundial se convierte en un fundamentalismo de los derechos humanos tan sólo si proporciona a una intervención, que de hecho no es más que una lucha de una parte contra otra, legitimación moral con la cobertura de una aparente legitimación jurídica. En tales casos la organización mundial (o la alianza que actúa en su nombre) comete un "engaño", porque lo que en verdad es un enfrentamiento militar entre las partes bélicas se hace pasar por medidas de tipo policial justificadas por leyes y sentencias. "Determinadas apelaciones justificadas moralmente amenazan con adoptar rasgos fundamentalistas si se orientan no a la puesta en marcha de procedimientos jurídicos para la (positivación) aplicación y ejecución de los derechos humanos, sino a usar directamente el esquema interpretativo con el que imputar violaciones de derechos humanos, y si se convierten en las únicas fuentes de las sanciones exigidas» ${ }^{60}$.

${ }^{59}$ Cfr. J. Habermas, Kleine Politische Schriften $1-I V$, Franefort, 1981, pp. 328-339.

Ka Klaus Günther, "Kampl gegen das Böse? Wider die ethische Aufrüstung der Kriminalpolitik», en Kritische Justiz, 27, 1994, pp. 135-157 (el añadido entre paréntesís es mío). 
C. Schmitt defiende además la afirmación de que la juridificación de la política expansiva más allá de las fronteras estatales, esto es, la puesta en vigor de los derechos humanos en un escenario dominado hasta ahora por el poder militar, tiene como consecuencia siempre y necesariamente ese fundamentalismo de los derechos humanos. Esta afirmación es falsa porque se basa en la falsa premisa de que los derechos humanos son de naturaleza moral, esto es, que la puesta en vigor de los derechos humanos significa una moralización. La mencionada parte problemática de la juridificación de las relaciones internacionales no consiste, por tanto, en que una acción hasta ahora concebida como política debe caer en adelante bajo las categorías morales. A diferencia de la moral el código jurídico no exige en absoluto una valoración moral directa según los criterios de «bueno» y «malo». Klaus Günther aclara el punto central: «Que una interpretación política (en el sentido de Carl Schmitt) de una conducta contra los derechos humanos esté bloqueada no puede significar que se pueda dar en su lugar una interpretación directamente moral» ${ }^{61}$. Los derechos humanos no pueden ser confundidos con los derechos morales.

I. a diferencia entre derecho y moral en la que insiste Günther tampoco significa que el derecho positivo no tenga ningún contenido moral. Sobre el procedimiento democrático de la legislación política fluyen también entre otros argumentos morales que están en la fundamentación de la creación de normas y por eso en el propio dercho. Como Kant ya había visto, el derecho se diferencia de la moral por medio de las propiedades formales de la legalidad. A través de ella una parte de la conducta enjuiciable moralmente (como, p. ej., las intenciones y los motivos) son apartados de la regulación jurídica en general. Pero ante todo el código jurídico vincula las sentencias y sanciones de las instancias competentes para la protección de los afectados a las condiciones revisables intersubjetivamente de los procedimientos del Estado de derecho. Mientras que la persona moral ante la instancia interna del examen de conciencia está ahí, por así decir, desnuda, la persona jurídica permanece recubierta al abrigo de los derechos de libertad - bien fundados moralmente- La respuesta correcta al peligro de la moralización directa de la política de expansión es más bien «no la desmoralización de la política, sino la transformación democrática de la moral en un sistema positivizado de derechos con procedimientos jurídicos para su aplicación y cjecución» ${ }^{62}$. El fundamentalismo de los derechos humanos no se evita mediante la renuncia a la política de los derechos humanos, sino sólo mediante la transformación iuscosmopolita del estado de naturaleza entre los Estados en un orden jurídico.

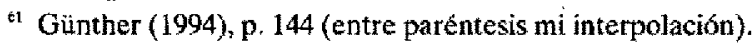

*2 Güther (1994), p. 144
} 